Jong, H.J.I. de, Vandebriel, R.J., Saldi, S.R.F., Dijk, L. van, Loveren, H. van, Cohen Tervaert, J.W., Klungel, O.H. Angiotensin-converting enzyme inhibitors or angiotensin II receptor blockers and the risk of developing rheumatoid arthritis in antihypertensive drug users. Pharmacoepidemiology and Drug Safety: 2012, 21(8), 835-843

\begin{tabular}{|l|l|}
\hline Postprint Version & 1.0 \\
\hline Journal website & http://dx.doi.org/10.1002/pds.3291 \\
\hline Pubmed link & $\underline{\text { http://www.ncbi.nlm.nih.gov/pubmed/22674737 }}$ \\
\hline DOI & $10.1002 /$ pds.3291 \\
\hline This is a NIVEL certified Post Print, more info at http://www.nivel.eu
\end{tabular}

\title{
Angiotensin-converting enzyme inhibitors or angiotensin II receptor blockers and the risk of developing rheumatoid arthritis in antihypertensive drug users $\dagger$ t
}

\author{
Hilda J. I. DE Jong1,2,3, Rob J. VANDEBRiel1, Siti R. F. SALdi3, Liset VAN DiJK4, HenK \\ VAN LOVEREN1,2, JAN WiLlem COHEN TERVAERT5, Olaf H. Klungel3, *
}

\begin{abstract}
Purpose: Angiotensin-converting enzyme (ACE) inhibitors and angiotensin II receptor blockers (ARBs) are effective in the treatment of cardiovascular disease. Next to effects on hypertension and cardiac function, these drugs have anti-inflammatory and immunomodulating properties which may either facilitate or protect against the development of autoimmunity, potentially resulting in autoimmune diseases. Therefore, we determined in the current study the association between ACE inhibitor and ARB use and incident rheumatoid arthritis (RA).

Methods: A matched case-control study was conducted among patients treated with antihypertensive drugs using the Netherlands Information Network of General Practice (LINH) database in 2001-2006. Cases were patients with a first-time diagnosis of RA. Each case was matched to five controls for age, sex, and index date, which was selected 1 year before the first diagnosis of RA. ACE inhibitor and ARB exposure was considered to be any prescription issued in the period before index date. Logistic regression analysis was used to estimate odds ratios (ORs) and their 95\% confidence intervals (CI).

Results: Our study included 211 cases and 667 matched controls. After controlling for potential confounders, ever use of ACE inhibitors or ARBs was not associated with incident RA (adjusted ORs [95\%CI], 0.99 [0.55-1.79] and 1.02 [0.67-1.56], respectively). The adjusted ORs $(95 \% \mathrm{CI})$ for current and past use of ACE inhibitors were 1.18 (0.75-1.85) and 0.61 (0.28-1.35). For current and past use of ARBs, these adjusted ORs $(95 \% \mathrm{CI})$ were $1.40(0.80-2.45)$ and 0.29 (0.05-1.67), respectively. No duration and dose-effect relationship was observed.

Conclusions: ACE inhibitor or ARB use is not associated with incident RA.
\end{abstract}


Jong, H.J.I. de, Vandebriel, R.J., Saldi, S.R.F., Dijk, L. van, Loveren, H. van, Cohen Tervaert, J.W., Klungel, O.H. Angiotensin-converting enzyme inhibitors or angiotensin II receptor blockers and the risk of developing rheumatoid arthritis in antihypertensive drug users. Pharmacoepidemiology and Drug Safety: 2012, 21(8), 835-843

\section{INTRODUCTION}

Angiotensin-converting enzyme (ACE) inhibitors and angiotensin II receptor blockers (ARBs) have been reported to reduce mortality and morbidity from cardiovascular events among patients with hypertension, renal, and cardiovascular diseases. ${ }^{[1-7]}$ In addition to their effects on blood pressure, cardiac function, and antiproteinuric effect, ACE inhibitors and ARBs have anti-inflammatory and immunomodulating properties. ${ }^{[8-11]}$ Open-label studies with rheumatoid arthritis (RA) patients and experimental studies in collagen-induced arthritis suggested a beneficial effect of ACE inhibitors and ARBs in arthritis. ${ }^{[12-15]}$ Similarly, ACE inhibitors and ARBs reduce the incidence and severity of experimental autoimmune myocarditis. ${ }^{[16]}$ Otherwise, it has been postulated that the immunomodulating effects of ACE inhibitors may facilitate autoimmune responses. ${ }^{[17,18]}$ Indeed, several case reports have suggested that ACE inhibitors may facilitate the development of autoantibodies $^{[19-21]}$ and autoimmune diseases such as lupus-like syndrome, vasculitis, and pemphigus. ${ }^{[22-42]}$ Furthermore, one patient with ARB-associated pemphigus has been reported. ${ }^{[43]}$

The proposed mechanisms by which ACE inhibitors or ARBs may facilitate and be protective for RA are unclear.

The anti-inflammatory effects of ACE inhibitors and ARBs are likely due to changes in cellular immunity ${ }^{[8]}$ and to inhibiting adhesion molecule upregulation, chemotaxis, and the release of cytokines by immune cells. ${ }^{[44-46]}$ As a result, ARBs and ACE inhibitors may interfere with leukocyte-endothelial cell adhesion and thereby prevent the influx of inflammatory cells in the inflamed synovial membrane and at the cartilage-pannus junction.

Importantly, Shao and colleagues showed in a study with angiotensin-II-infused hypertensive rats elevated levels of the T-helper cells 1 (Th1) cytokine interferon- $\gamma$ and decreased levels of Th2 cytokine IL-4. By administering in these rats an ARB, the imbalance of Th subsets was corrected. ${ }^{[47]}$ Furthermore, Platten and colleagues demonstrated in an animal model of experimental autoimmune encephalitis, mimicking multiple sclerosis, that ACE inhibitors modulate this disease by suppressing autoreactive Th1 and Th17 cells and promoting T-regulatory cells. ${ }^{[8]}$ Otherwise, Coelho dos Santos and colleagues found that ACE inhibitors increase the intensity of Trypanosoma cruzi infection of human monocytes and decreases the expression of the modulatory cytokine IL-10 while inducing Th17 cells ${ }^{[17]}$ and hence may promote RA, psoriasis, and psoriatic arthritis. ${ }^{[48-50]}$ Finally, studies have shown that captopril blocks activation-induced apoptosis in $\mathrm{T}$ cells ${ }^{[18,51]}$ and hence may interfere with clonal deletion and disturb the maintenance of self-tolerance, thus facilitating autoimmunity. ${ }^{[17,18]}$

The objective of our study was to investigate whether the use of ACE inhibitors or ARBs increase or decrease incident RA in a large observational study.

\section{METHODS}

\section{Study population}

Data for this study were obtained from the Netherlands Information Network of General Practice (LINH), a database derived from general practices that records data on morbidity, drug prescriptions, and referrals on a continuous basis in electronic medical records. The LINH includes 350000 patients who were registered at 85 
Jong, H.J.I. de, Vandebriel, R.J., Saldi, S.R.F., Dijk, L. van, Loveren, H. van, Cohen Tervaert, J.W., Klungel, O.H. Angiotensin-converting enzyme inhibitors or angiotensin II receptor blockers and the risk of developing rheumatoid arthritis in antihypertensive drug users. Pharmacoepidemiology and Drug Safety: 2012, 21(8), 835-843

practices from 2001 through $2006 .{ }^{[52]}$ Prescription data were classified according to the Anatomical Therapeutic and Chemical (ATC) classification, ${ }^{[53]}$ and morbidity was coded by using the International Classification of Primary Care (ICPC) scheme. ${ }^{[54]}$ The study was carried out according to Dutch legislation on privacy. The privacy regulation of the study was approved by the Dutch Data Protection Authority. According to Dutch legislation, neither obtaining informed consent nor approval by a medical ethics committee was obligatory for observational studies.

\section{Study design}

We performed a nested, matched case-control study among patients treated with antihypertensive drugs. Under our definition of antihypertensive drugs, we included miscellaneous antihypertensive drugs (ATC code C02), thiazide diuretics (ATC code C03), beta-blocking agents (ATC code C07), calcium channel blockers (ATC code C08), ACE inhibitors (ATC code C09A/C09B), and ARBs (ATC code C09C/C09D).

\section{Case definition}

All patients who were first diagnosed with RA and were registered with a general practitioner (GP) for at least 1 year at index date were included in the study. Subsequent diagnoses of RA were disregarded. The date exactly 1 year before the date of first-time diagnosis of RA was subsequently used as index date because the diagnosis is usually made after the disease has been symptomatic for some period. ${ }^{[55}$,

${ }^{56]}$ When the index date was shifted 1 year before the first-time diagnosis of RA, patients still had to have a medical history of at least 1 year before this new index date. Patients were considered as having a diagnosis of RA if the first-time diagnosis registered by GP was verified by a referral to a rheumatologist by the use of at least one prescription of disease modifying antirheumatoid drug (DMARD) or two or more prescriptions of systemic corticosteroids after index date. ${ }^{[57]}$

Patients were excluded from the study if they had a medical record of ankylosing spondylitis (ICPC code L88.2) or received at least one prescription of DMARDs before index date, if they had a diagnosis of RA by the GP with no confirmation according to the mentioned criteria, or if they had no registered medical history for 1 year. ${ }^{[57]}$

\section{Control selection}

Of the antihypertensive drug users, five controls were matched to each RA case on age (within 5 years), sex, and index date. Controls were required to be registered at least 1 year in the general practice before index date to minimise information bias. The exclusion criteria used in case selection were applied to controls.

\section{Definition of exposure}

Using data on prescription dispensing date and days supplied, we determined the exposure to ACE inhibitors and ARBs for each patient in the study. All the patients were users of at least one antihypertensive drug. Current use was defined as receiving at least one prescription of ACE inhibitors and ARBs within 6 months before index date, and past use was defined as receiving a prescription of $\mathrm{ACE}$ inhibitors and ARBs but discontinued treatment more than 6 months before index date. Patients, who were current or past users of ACE inhibitors and ARBs simultaneously, were categorised as a separate group. Patients who were not users of ACE inhibitors or ARBs but were users of another antihypertensive drug such as thiamine diuretics, calcium antagonists, and beta blockers were used as the reference 
Jong, H.J.I. de, Vandebriel, R.J., Saldi, S.R.F., Dijk, L. van, Loveren, H. van, Cohen Tervaert, J.W., Klungel, O.H. Angiotensin-converting enzyme inhibitors or angiotensin II receptor blockers and the risk of developing rheumatoid arthritis in antihypertensive drug users. Pharmacoepidemiology and Drug Safety: 2012, 21(8), 835-843

category. The expected duration of ACE inhibitor and ARB use until index date was based on treatment time and prescribed drug supply (determined by the number of prescribed tablets), and was divided into three categories: [1] 1-365 days, [2] 3661095 days, and [3] more than 1095 days. We calculated the dose of ACE inhibitors and ARBs according to the defined daily dose (DDD), which is the average daily dose of a drug for its main indication in adults ${ }^{[51]}$ (1 DDD corresponds with captopril $50 \mathrm{mg}$, enalapril $10 \mathrm{mg}$, lisinopril $10 \mathrm{mg}$, perindopril $4 \mathrm{mg}$, ramipril $2.5 \mathrm{mg}$, quinapril $15 \mathrm{mg}$, fosinopril $15 \mathrm{mg}$, losartan $50 \mathrm{mg}$, valsartan $80 \mathrm{mg}$, irbesartan $0.15 \mathrm{~g}$, candesartan $8 \mathrm{mg}$, telmisartan $40 \mathrm{mg}$, and olmesartan medoxomil $20 \mathrm{mg}$ ). Based on almost equal distributions of ACE inhibitor and ARB use, ACE inhibitor exposure was categorised into three categories of less than 0.75 DDD per day, $0.75-1.25$ DDD per day, and more than 1.25 DDD per day, and ARB exposure was categorised as less than 1.0 DDD per day and more than 1.0 DDD per day to assess a potential dose-response relationship.

\section{Potential confounders}

Potential confounders included prescriptions within 6 months preceding the index date for nonsteroidal anti-inflammatory drugs (NSAIDs), corticosteroids, proton pump inhibitors, statins, aspirin, antibiotics, hormone replacement therapy, antidepressants, calcium antagonists, and thiazide diuretics and comorbidities including diabetes, hyperlipidaemia, cardiovascular disease, and chronic obstructive pulmonary disease (COPD) ${ }^{[58]}$ Patients were classified as diabetic when they had a diagnosis of diabetes (identified by ICPC codes T89 or T90) or when they received antidiabetic therapy before index date. Hyperlipidaemia was considered present when the patient had a medical record of hyperlipidaemia (identified by ICPC code T93) or used lipid-lowering drugs prior to the index date. COPD and cardiovascular disease were identified by ICPC code R95 and ICPC codes K71, K73-K84, K89, K90, K92-K96, and K99, respectively.

\section{Statistical analysis}

Continuous variables were expressed as mean \pm standard deviation, and categorical variables were expressed as frequencies and percentages. For baseline characteristics, continuous data were analysed by Student's $t$-test and categorical data by chi-square test or Fisher exact test when appropriate. Logistic regression conditioned on the matching factors was used to study the association between ACE inhibitor and ARB use and the risk of RA. Odds ratios and $95 \%$ confidence intervals (95\% CIs) were estimated. We evaluated the effects of ever use, current and past use, and specific type, duration and DDDs of ACE inhibitor and ARB on the risk of developing RA. In addition to controlling for age, sex, and calendar time by matching, estimates were adjusted for the mentioned confounders. Furthermore, we evaluated the confounding effects of aspirin, statins, antibiotics, hormone replacement therapy, corticosteroids, antidepressants, and thiazide diuretics and diabetes, hyperlipidaemia, and COPD, but we did not include these covariates in the regression models because we did not observe more than $10 \%$ change in the estimate of the exposure-outcome association by adding each time one of these variables into the model. ${ }^{[59]}$ A $p$ value of $\leq 0.05$ was considered statistically significant. We used SAS version 9.2 (SAS Institute, Cary, North Carolina) to analyse the data. We performed a sensitivity analysis where we investigated the influence of thiazide diuretics on the association between ACE inhibitors/ARB and RA because several studies have demonstrated the association 
Jong, H.J.I. de, Vandebriel, R.J., Saldi, S.R.F., Dijk, L. van, Loveren, H. van, Cohen Tervaert, J.W., Klungel, O.H. Angiotensin-converting enzyme inhibitors or angiotensin II receptor blockers and the risk of developing rheumatoid arthritis in antihypertensive drug users. Pharmacoepidemiology and Drug Safety: 2012, 21(8), 835-843

between thiazide diuretics and autoimmune reactions. ${ }^{[60,61]}$ To explore the influence of inclusion of prevalent cases in the study, we performed two sensitivity analyses where we shifted the index date exactly 2 and 3 years before the first-time diagnosis of RA. Two sensitivity analyses were performed to examine the effect of misclassification of patients by changing the definition of the outcome (RA). First, we varied the definition of the outcome (RA), specified as first-time diagnosis of RA and a referral to a rheumatologist and a prescription of DMARDs after index date (irrespective of the use of corticosteroids), a definition used in another study. ${ }^{[62]}$ Second, we investigated the influence of the inclusion of patients with psoriatic arthritis and performed an analysis that excluded patients with a medical record for psoriasis.

\section{RESULTS}

The study population consisted of 57457 patients who used at least one prescription of antihypertensive drugs during the study period from 2001 through 2006 . Of those, 877 patients had a first-time diagnosis of RA. Of these RA patients, 72 patients were excluded because they used at least one prescription of DMARDs before index date and 269 patients because they had no minimum registered medical history of 1 year. In addition, 325 patients were excluded from the study because the first-time diagnosis of RA by the GP was not confirmed according to the predefined criteria. After these exclusions, we identified 211 eligible RA patients that were matched to 667 controls.

Characteristics of the study population at the index date are described in Table ${ }^{1}$. The average age of the study population was 65 years, and approximately $67 \%$ were women. RA patients used more often corticosteroids, NSAIDs, antidepressants, and proton pump inhibitors and were more often diagnosed with COPD than were controls. The duration of registration with the GP was approximately 11.2 years in RA patients and 10.5 years in controls. Table ${ }^{2}$ shows that ACE inhibitor use or ARB use prior to the index date was not associated with incident RA (adjusted odds ratios [ORs], 1.02 [95\%CI, 0.59-1.78]) and (adjusted OR, 1.02 [95\%CI, 0.69-1.51]), respectively. The adjusted ORs $(95 \% \mathrm{CI})$ of incident RA associated with current and past use of ACE inhibitors were 1.15 (0.76-1.74) and 0.70 (0.34-1.47), respectively. Current and past use of ARBs were not associated with incident RA (adjusted ORs [95\%CI], 1.39 [0.82-2.33] and 0.29 [0.06-1.96], respectively). In addition, current use and past use of the combination therapy of ACE inhibitors and ARBs were not associated with incident RA.

\section{[TABLE 1. AND TABLE 2]}

No relation between the duration and intensity of use of ACE inhibitors or ARBs, expressed as days of use and numbers of DDD, and the risk of developing RA was observed $\left(\right.$ Table $\left.^{3}\right)$. Stratifying results according to the type of ACE inhibitor and ARB use showed no risk differences between ACE inhibitor or ARB users and nonusers (data not shown). 
Jong, H.J.I. de, Vandebriel, R.J., Saldi, S.R.F., Dijk, L. van, Loveren, H. van, Cohen Tervaert, J.W., Klungel, O.H. Angiotensin-converting enzyme inhibitors or angiotensin II receptor blockers and the risk of developing rheumatoid arthritis in antihypertensive drug users. Pharmacoepidemiology and Drug Safety: 2012, 21(8), 835-843

[TABLE 3]

\section{Sensitivity analyses}

The risk of RA associated with ACE inhibitors or ARBs was similar for subjects using thiazide diuretics and subjects not using thiazide diuretics. When we shifted the index date 2 and 3 years before the first-time diagnosis of RA, we found no association between ACE inhibitor and ARB use and incident RA (data not shown), and no difference in the distribution of NSAID and corticosteroid use between cases and controls was observed. When the analysis was restricted to RA patients referred to a rheumatologist or received at least one prescription of a DMARD after index date, the adjusted ORs $(95 \% \mathrm{CI})$ for ACE inhibitor and ARB use and the risk of developing RA were $0.92(0.45-1.87)$ and $0.89(0.36-1.79)$, respectively. To exclude possible bias by accidental inclusion of patients with psoriatic arthritis among RA patients, we repeated the analysis after removing the patients who had a recorded diagnosis of psoriasis. Results were consistent with all other analyses (adjusted ORace inhibitor, 1.03 [95\%CI, 0.61-1.85]; adjusted ORARB, 1.06 [95\%CI, 0.68 1.53]; and adjusted ORACE inhibitor and ARB, 1.63 [95\%CI, 0.74-3.57]).

\section{DISCUSSION}

The present study did not demonstrate an association between ACE inhibitor and ARB use and the risk of developing RA. The effect was consistent when we defined the exposure to ACE inhibitors and ARBs as current and past use and duration of use. Furthermore, no dose-response effect was observed. Thus, our data do not support the hypothesis that ACE inhibitors and ARBs either facilitate or protect against RA.

To our knowledge, this is the first observational study investigating the influence of ACE inhibitor and ARB use and incident RA. Evidence for the association between ACE inhibitor and/or ARB use and the occurrence of autoimmune diseases was derived from case reports of lupus-like disease, vasculitis, and pemphigus. ${ }^{[22-43]}$ In these case reports, the commonly prescribed ACE inhibitors such as captopril and enalapril were often reported as a suspected drug for the occurrence of these autoimmune diseases. In our study, however, we observed no difference in the risk estimates of individual ACE inhibitors and the risk of developing RA.

Several studies have shown the beneficial effects of ARB and ACE inhibitor use in animal models of induced arthritis. ${ }^{[13,14,63,64]}$ Furthermore, in an open study of patients with active RA treated with captopril, reductions in joint symptoms, the number of swollen joints, and reduced levels of C-reactive protein (CRP) were found. ${ }^{[12]}$ In addition, in an open study using pentopril, no clinical improvement in patients with RA was observed, although CRP levels decreased. ${ }^{[65]}$ Furthermore, ARB use in RA patients was found to be associated with a significant reduction in erythrocyte sedimentation rate. ${ }^{[15]}$ Findings are, however, inconclusive. ${ }^{[15,66]}$ Several limitations of our study should be considered in the interpretation of these results. First, the definition of RA in our study was based on GPs' diagnosis, a referral to a rheumatologist, or prescriptions of DMARDs and/or corticosteroids after index date. We may have used a relatively sensitive, but nonspecific, diagnosis of RA because no specific ICPC codes were available for other rheumatic diseases, for example, psoriatic arthritis. Furthermore, no data on examinations such as the presence of anti-cyclic citrullinated peptide antibodies or X-ray of hands and feet 
Jong, H.J.I. de, Vandebriel, R.J., Saldi, S.R.F., Dijk, L. van, Loveren, H. van, Cohen Tervaert, J.W., Klungel, O.H. Angiotensin-converting enzyme inhibitors or angiotensin II receptor blockers and the risk of developing rheumatoid arthritis in antihypertensive drug users. Pharmacoepidemiology and Drug Safety: 2012, 21(8), 835-843

were available for making a diagnosis of RA. Therefore, false positives, meaning that not all cases were true cases of RA, may have diluted the results of our study, and we may have underestimated the OR of RA. However, our results remained unchanged when analyses were restricted to RA patients referred to a rheumatologist or those who received DMARDs after their first-time diagnosis, or when we excluded patients with a diagnosis for psoriasis, or when we modified the index date exactly 2 and 3 years before the first-time diagnosis of RA. Because of limited power of our study population, we used an index date exactly 1 year before the first-time diagnosis of RA. When the analysis was restricted to RA patients referred to a rheumatologist and received at least one prescription of a DMARD after index date, the results were consisted with all other analyses. Our findings indicate no association between ACE inhibitor and ARB use and incident RA when we used other criteria for defining RA in our study.

Second, our study was observational, and patients were not randomly assigned to antihypertensive therapy. Physicians and patients selected antihypertensive drug therapies, and this may have introduced bias. We think, however, that it is unlikely that this bias has influenced our results because no differences between cases and controls in the prescriptions of other antihypertensive drugs were observed. Third, misclassification of ACE inhibitor and ARB use may be a concern in this study because we used computerised prescription data from the GP. Patients may have been nonadherent to the treatment of ACE inhibitors or ARBs and therefore could have used less ACE inhibitors or ARBs than prescribed. However, this misclassification is likely to be nondifferential between cases and controls and may have resulted in an underestimation of the association between use of ACE inhibitors and/or ARBs and RA. Fourth, selection bias may have been introduced in this study because GPs could have paid more attention to comorbidities of RA patients. Yet, the average duration in the registry is almost equal between RA and controls, and therefore, the patients in our study had similar opportunities to have been prescribed an ACE inhibitor or ARB. Further limitations include the lack of information on dietary intake, physical activity, and smoking and limited data on other examinations (e.g., blood pressure, lipid levels). ${ }^{[67-69]}$ From the approximately 57457 eligible patients who were taking antihypertensive medication, we ultimately included 211 RA patients in our study. Due to several exclusions, our results may not necessarily be extrapolated to all treated hypertensive patients. In addition, the group of users of ACE inhibitors and ARBs in our study was relatively small.

Strengths of our study include the use of different classes of antihypertensive drugs and the use of a computerised database, allowing us to use routinely recorded medical and prescription data from GPs. Consequently, recall bias was minimised. Another strength of our study is its inclusion of patients who were prescribed an antihypertensive drug. By including only these patients, we have ensured that prognostic factors such as cardiovascular risk factors (e.g., hypertension) were almost evenly distributed between the RA patients and controls. ${ }^{[70]}$ Furthermore, because hypertension may be considered as an immune-mediated disease ${ }^{[71,72]}$ hypertension-related immunological abnormalities relevant for the development of RA were probably also equally distributed between both groups. Nonetheless, hypertension is more prevalent in RA patients than in the general population, ${ }^{[73]}$ and theoretically, in view of their immunomodulating capacities, the use of ACE inhibitors and/or ARBs might prevent the development of RA. 
Jong, H.J.I. de, Vandebriel, R.J., Saldi, S.R.F., Dijk, L. van, Loveren, H. van, Cohen Tervaert, J.W., Klungel, O.H. Angiotensin-converting enzyme inhibitors or angiotensin II receptor blockers and the risk of developing rheumatoid arthritis in antihypertensive drug users. Pharmacoepidemiology and Drug Safety: 2012, 21(8), 835-843

In conclusion, the present study suggests that there is no association between incident RA and ACE inhibitor or ARB use. Our results indicate that the beneficial effects of ACE inhibitors and ARBs studied in patients with RA were not observed among hypertensive patients without clinically manifest RA. Furthermore, our study does not underline findings from individual case reports suggesting that ACE inhibitors and ARBs may facilitate the development of autoimmune diseases. Based on these findings, we believe that both ACE inhibitors and ARBs are considered to be safe for patients with a risk of developing RA. Further research using larger sample size and a prospective study design are needed to confirm our findings. It is of interest to replicate the design of this study to assess the association with psoriasis and psoriatic arthritis.

\section{CONFLICT OF INTEREST}

The division of Pharmacoepidemiology \& Clinical Pharmacology employing author H. J. I. dJ. has received unrestricted funding for pharmacoepidemiological research from GlaxoSmithKline, Novo Nordisk, and the private-public funded Top Institute Pharma and the Dutch Medicines Evaluation board. These grants have no relation with the research on which the submitted manuscript is based.

Dr Klungel has been consultant to Sanofi-Aventis on issues not related to this manuscript. The division of Pharmacoepidemiology \& Clinical Pharmacology employing author O. H. K. has received unrestricted funding for pharmacoepidemiological research from GlaxoSmithKline, Novo Nordisk, and the private-public funded Top Institute Pharma and the Dutch Medicines Evaluation board. These grants have no relation with the research on which the submitted manuscript is based.

The division of Pharmacoepidemiology \& Clinical Pharmacology employing author S. R. F. S. has received unrestricted funding pharmacoepidemiological research from GlaxoSmithKline, Novo Nordisk, and the private-public funded Top Institute Pharma and the Dutch Medicines Evaluation board. These grants have no relation with the research on which the submitted manuscript is based.

\section{ACKNOWLEDGEMENTS}

The authors thank the staff of LINH for their help in the data collection and data extraction and R. Janssen for her helpful suggestions.

The National Institute for Public Health and the Environment funded this study (Project S340040).

\section{REFERENCES}

1 Montecucco F, Mach F. Statins, ACE inhibitors and ARBs in cardiovascular disease. Best Pract Res Clin Endocrinol Metab 2009; 23(3): 389-400.

2 Yusuf S, Sleight P, Pogue J, Bosch J, Davies R, Dagenais G. Effects of an angiotensinconverting-enzyme inhibitor, ramipril, on cardiovascular events in high-risk patients. The Heart Outcomes Prevention Evaluation Study Investigators. N Engl J Med 2000; 342(3): 145-153.

3 Fox KM. EURopean trial On reduction of cardiac events with Perindopril in stable coronary Artery disease Investigators. Efficacy of perindopril in reduction of cardiovascular events among patients with stable coronary artery disease: randomised, double-blind, placebocontrolled, multicentre trial (the EUROPA study). Lancet 2003; 362(9386): 782-788. 
Jong, H.J.I. de, Vandebriel, R.J., Saldi, S.R.F., Dijk, L. van, Loveren, H. van, Cohen Tervaert, J.W., Klungel, O.H. Angiotensin-converting enzyme inhibitors or angiotensin II receptor blockers and the risk of developing rheumatoid arthritis in antihypertensive drug users. Pharmacoepidemiology and Drug Safety: 2012, 21(8), 835-843

4 Dahlof B, Devereux RB, Kjeldsen SE, et al. Cardiovascular morbidity and mortality in the Losartan Intervention For Endpoint reduction in hypertension study (LIFE): a randomised trial against atenolol. Lancet 2002; 359(9311): 995-1003.

5 Pfeffer MA, Swedberg K, Granger CB, et al. Effects of candesartan on mortality and morbidity in patients with chronic heart failure: the CHARM-Overall programme. Lancet 2003; 362(9386): 759-766.

6 Chobanian AV, Bakris GL, Black HR, et al. Seventh report of the Joint National Committee on Prevention, Detection, Evaluation, and Treatment of High Blood Pressure. Hypertension 2003; 42(6): 1206-1252.

7 MacKinnon M, Shurraw S, Akbari A, Knoll GA, Jaffey J, Clark HD. Combination therapy with an angiotensin receptor blocker and an ACE inhibitor in proteinuric renal disease: a systematic review of the efficacy and safety data. Am J Kidney Dis 2006; 48(1): 8-20.

8 Platten M, Youssef S, Hur EM, et al. Blocking angiotensin-converting enzyme induces potent regulatory T cells and modulates TH1- and TH17-mediated autoimmunity. Proc Natl Acad Sci U S A 2009; 106(35): 14948-14953.

9 Stegbauer J, Lee DH, Seubert S, et al. Role of the renin-angiotensin system in autoimmune inflammation of the central nervous system. Proc Natl Acad Sci U S A 2009; 106(35): 14942-14947.

10 Abd Alla J, Langer A, Elzahwy SS, Arman-Kalcek G, Streichert T, Quitterer U. Angiotensin-converting enzyme inhibition down-regulates the pro-atherogenic chemokine receptor 9 (CCR9)-chemokine ligand 25 (CCL25) axis. J Biol Chem 2010; 285(30): 2349623505.

11 Fliser D, Buchholz K, Haller H. EUropean Trial on Olmesartan and Pravastatin in Inflammation and Atherosclerosis (EUTOPIA) Investigators. Antiinflammatory effects of angiotensin II subtype 1 receptor blockade in hypertensive patients with microinflammation. Circulation 2004; 110(9): 1103-1107.

12 Martin MF, Surrall KE, McKenna F, Dixon JS, Bird HA, Wright V. Captopril: a new treatment for rheumatoid arthritis? Lancet 1984; 1(8390): 1325-1328.

13 Sagawa K, Nagatani K, Komagata Y, Yamamoto K. Angiotensin receptor blockers suppress antigen-specific $\mathrm{T}$ cell responses and ameliorate collagen-induced arthritis in mice. Arthritis Rheum 2005; 52(6): 1920-1928.

14 Dalbeth N, Edwards J, Fairchild S, Callan M, Hall FC. The non-thiol angiotensinconverting enzyme inhibitor quinapril suppresses inflammatory arthritis. Rheumatology (Oxford) 2005; 44(1): 24-31.

15 Perry ME, Chee MM, Ferrell WR, Lockhart JC, Sturrock RD. Angiotensin receptor blockers reduce erythrocyte sedimentation rate levels in patients with rheumatoid arthritis. Ann Rheum Dis 2008; 67(11): 1646-1647.

16 Godsel LM, Leon JS, Wang K, Fornek JL, Molteni A, Engman DM. Captopril prevents experimental autoimmune myocarditis. J Immunol 2003; 171(1): 346-352.

17 Coelho dos Santos JS, Menezes CA, Villani FN, et al. Captopril increases the intensity of monocyte infection by Trypanosoma cruzi and induces human T helper type 17 cells. Clin Exp Immunol 2010; 162(3): 528-536.

18 Odaka C, Mizuochi T. Angiotensin-converting enzyme inhibitor captopril prevents activation-induced apoptosis by interfering with T cell activation signals. Clin Exp Immunol 2000; 121(3): 515-522.

19 Kallenberg CG, Hoorntje SJ, Smit AJ, et al. Antinuclear and antinative DNA antibodies during captopril treatment. Acta Med Scand 1982; 211(4): 297-300.

Direct Link:

20 Reidenberg MM, Case DB, Drayer DE, Reis S, Lorenzo B. Development of antinuclear antibody in patients treated with high doses of captopril. Arthritis Rheum 1984; 27(5): 579581.

21 Schwartz D, Pines A, Averbuch M, Levo Y. Enalapril-induced antinuclear antibodies. Lancet 1990; 336(8708): 187.

22 Patri P, Nigro A, Rebora A. Lupus erythematosus-like eruption from captopril. Acta Derm Venereol 1985; 65(5): 447-448.

23 Sieber C, Grimm E, Follath F. Captopril and systemic lupus erythematosus syndrome. BMJ 1990; 301(6753): 669. 
Jong, H.J.I. de, Vandebriel, R.J., Saldi, S.R.F., Dijk, L. van, Loveren, H. van, Cohen Tervaert, J.W., Klungel, O.H. Angiotensin-converting enzyme inhibitors or angiotensin II receptor blockers and the risk of developing rheumatoid arthritis in antihypertensive drug users. Pharmacoepidemiology and Drug Safety: 2012, 21(8), 835-843

24 Bertin P, Kamdem J, Bonnet C, Arnaud M, Treves R. Captopril-induced lupus. Clin Exp Rheumatol 1993; 11(6): 695.

25 Pelayo M, Vargas V, Gonzales A, Vallano A, Esteban R, Guardia J. Drug-induced lupuslike reaction and captopril. Ann Pharmacother 1993; 27(12): 1541-1542.

26 Fernandez-Diaz ML, Herranz P, Suarez-Marrero MC, Borbujo J, Manzano R, Casado M. Subacute cutaneous lupus erythematosus associated with cilazapril. Lancet 1995; 345(8946): 398.

27 Ratliff NB 3rd. Captopril induced lupus. J Rheumatol 2002; 29(8): 1807-1808.

28 Disdier P, Harle JR, Verrot D, Jouglard J, Weiller PJ. Adult Schonlein-Henoch purpura after lisinopril. Lancet 1992; 340(8825): 985.

29 Moots RJ, Keeling PJ, Morgan SH. Adult Schonlein-Henoch purpura after enalapril. Lancet 1992; 340(8814): 304-305.

30 Goncalves R, Cortez Pinto H, Serejo F, Ramalho F. Adult Schonlein-Henoch purpura after enalapril. J Intern Med 1998; 244(4): 356-357.

Direct Link:

31 Gupta S, Gandhi NM, Ferguson J. Cutaneous vasculitis secondary to ramipril. J Drugs Dermatol 2004; 3(1): 81-82.

32 Pinto GM, Lamarao P, Vale T. Captopril-induced pemphigus vegetans with CharcotLeyden crystals. J Am Acad Dermatol 1992; 27(2 Pt 2): 281-284.

33 Kaplan RP, Potter TS, Fox JN. Drug-induced pemphigus related to angiotensinconverting enzyme inhibitors. J Am Acad Dermatol 1992; 26(2 Pt 2): 364-366.

34 Ruocco V, Satriano RA, Guerrera V. "Two-step" pemphigus induction by ACE-inhibitors. Int J Dermatol 1992; 31(1): 33-36.

35 Kuechle MK, Hutton KP, Muller SA. Angiotensin-converting enzyme inhibitor-induced pemphigus: three case reports and literature review. Mayo Clin Proc 1994; 69(12): 11661171.

36 Bastiaens MT, Zwan NV, Verschueren GL, Stoof TJ, Nieboer C. Three cases of pemphigus vegetans: induction by enalapril--association with internal malignancy. Int J Dermatol 1994; 33(3): 168-171.

37 Butt A, Burge SM. Pemphigus vulgaris induced by captopril. Br J Dermatol 1995; 132(2): 315-316.

38 Vignes S, Paul C, Flageul B, Dubertret L. Ramipril-induced superficial pemphigus. Br J Dermatol 1996; 135(4): 657-658.

39 Buzon E, Perez-Bernal AM, de la Pena F, Rios JJ, Camacho F. Pemphigus foliaceus associated with cilazapril. Acta Derm Venereol 1998; 78(3): 227.

40 Ong CS, Cook N, Lee S. Drug-related pemphigus and angiotensin converting enzyme inhibitors. Australas J Dermatol 2000; 41(4): 242-246.

Direct Link:

41 Parodi A, Cozzani E, Milesi G, Drosera M, Rebora A. Fosinopril as a possible pemphigusinducing drug. Dermatology 2002; 204(2): 139-141.

42 Patterson CR, Davies MG. Pemphigus foliaceus: an adverse reaction to lisinopril. J Dermatolog Treat 2004; 15(1): 60-62.

43 Bae YI, Yun SJ, Lee SC, Park GT, Lee JB. Pemphigus foliaceus induced by an angiotensin II receptor blocker. Clin Exp Dermatol 2008; 33(6): 721-723.

44 Godsel LM, Leon JS, Engman DM. Angiotensin converting enzyme inhibitors and angiotensin II receptor antagonists in experimental myocarditis. Curr Pharm Des 2003; 9(9): 723-735.

45 Sukumaran V, Watanabe K, Veeraveedu PT, et al. Olmesartan, an AT1 antagonist, attenuates oxidative stress, endoplasmic reticulum stress and cardiac inflammatory mediators in rats with heart failure induced by experimental autoimmune myocarditis. Int $\mathrm{J}$ Biol Sci 2011; 7(2): 154-167.

46 Ruiz-Ortega M, Bustos C, Hernandez-Presa MA, Lorenzo O, Plaza JJ, Egido J. Angiotensin II participates in mononuclear cell recruitment in experimental immune complex nephritis through nuclear factor-kappa B activation and monocyte chemoattractant protein-1 synthesis. J Immunol 1998; 161(1): 430-439.

47 Shao J, Nangaku M, Miyata T, et al. Imbalance of T-cell subsets in angiotensin II-infused hypertensive rats with kidney injury. Hypertension 2003; 42(1): 31-38. 
Jong, H.J.I. de, Vandebriel, R.J., Saldi, S.R.F., Dijk, L. van, Loveren, H. van, Cohen Tervaert, J.W., Klungel, O.H. Angiotensin-converting enzyme inhibitors or angiotensin II receptor blockers and the risk of developing rheumatoid arthritis in antihypertensive drug users. Pharmacoepidemiology and Drug Safety: 2012, 21(8), 835-843

48 Miossec $P$. Interleukin-17 and Th17 cells: from adult to juvenile arthritis--now it is serious! Arthritis Rheum 2011; 63(8): 2168-2171.

Direct Link:

49 Blauvelt A. Psoriatic plaques and additional genetic links between IL-23 and psoriasis. J Invest Dermatol 2008; 128(5): 1064-1067.

50 Leipe J, Grunke M, Dechant C, et al. Role of Th17 cells in human autoimmune arthritis. Arthritis Rheum 2010; 62(10): 2876-2885.

51 Deas O, Dumont C, Mollereau B, et al. Thiol-mediated inhibition of FAS and CD2 apoptotic signaling in activated human peripheral T cells. Int Immunol 1997; 9(1): 117-125.

52 Verheij RA, Van Dijk CE, Stirbu-Wagner I, et al. Landelijk Informatienetwerk Huisartsenzorg. Feiten en cijfers over huisartsenzorg in Nederland. NIVEL/IQ, Utrecht/Nijmegen; 2009. http://www.linh.nl/ (accessed 14 November 2011).

53 ATC classification index with DDDs. WHO Collaborating Centre for Drug Statistics Methodology, 2008.

54 Lamberts H, Wood M. ICPC: International Classification of Primary Care. Oxford University Press: Oxford, 1987.

55 Chan KW, Felson DT, Yood RA, Walker AM. The lag time between onset of symptoms and diagnosis of rheumatoid arthritis. Arthritis Rheum 1994; 37(6): 814-820.

56 Palm O, Purinszky E. Women with early rheumatoid arthritis are referred later than men. Ann Rheum Dis 2005; 64(8): 1227-1228.

57 De Jong HJ, Klungel OH, van Dijk L, et al. Use of statins is associated with an increased risk of rheumatoid arthritis. Ann Rheum Dis 2011 Oct 6 [Epub ahead of print].

58 Pedersen M, Jacobsen S, Klarlund M, et al. Environmental risk factors differ between rheumatoid arthritis with and without auto-antibodies against cyclic citrullinated peptides. Arthritis Res Ther 2006; 8(4): R133.

59 Mickey RM, Greenland S. The impact of confounder selection criteria on effect estimation. Am J Epidemiol 1989; 129(1): 125-137.

60 Rubin RL. Drug-induced lupus. Toxicology 2005; 209(2): 135-147.

61 Chang C, Gershwin ME. Drugs and autoimmunity--a contemporary review and mechanistic approach. J Autoimmun 2010; 34(3): J266-J275.

62 Jick SS, Choi H, Li L, McInnes IB, Sattar N. Hyperlipidemia, statin use and the risk of developing rheumatoid arthritis. Ann Rheum Dis 2009; 68(4): 546-551.

63 Sakuta T, Morita Y, Satoh M, Fox DA, Kashihara N. Involvement of the renin-angiotensin system in the development of vascular damage in a rat model of arthritis: effect of angiotensin receptor blockers. Arthritis Rheum 2010; 62(5): 1319-1328.

64 Price A, Lockhart JC, Ferrell WR, Gsell W, McLean S, Sturrock RD. Angiotensin II type 1 receptor as a novel therapeutic target in rheumatoid arthritis: in vivo analyses in rodent models of arthritis and ex vivo analyses in human inflammatory synovitis. Arthritis Rheum 2007; 56(2): 441-447.

65 Bird HA, Le Gallez P, Dixon JS, et al. A clinical and biochemical assessment of a nonthiol ACE inhibitor (pentopril; CGS-13945) in active rheumatoid arthritis. J Rheumatol 1990; 17(5): 603-608.

66 Tikiz C, Utuk O, Pirildar T, et al. Effects of Angiotensin-converting enzyme inhibition and statin treatment on inflammatory markers and endothelial functions in patients with longterm rheumatoid arthritis. J Rheumatol 2005; 32(11): 2095-2101.

67 Hazes JM, Dijkmans BA, Vandenbroucke JP, de Vries RR, Cats A. Lifestyle and the risk of rheumatoid arthritis: cigarette smoking and alcohol consumption. Ann Rheum Dis 1990; 49(12): 980-982.

68 Plasqui G. The role of physical activity in rheumatoid arthritis. Physiol Behav 2008; 94(2): 270-275.

69 Sugiyama D, Nishimura K, Tamaki K, et al. Impact of smoking as a risk factor for developing rheumatoid arthritis: a meta-analysis of observational studies. Ann Rheum Dis 2010; 69(1): 70-81.

70 Klungel $\mathrm{OH}$, Martens EP, Psaty BM, et al. Methods to assess intended effects of drug treatment in observational studies are reviewed. J Clin Epidemiol 2004; 57(12): 12231231.

71 Cohen Tervaert JW. Hypertension: an autoimmune disease? Hypertens Res 2011; 34(4): 443-444. 
Jong, H.J.I. de, Vandebriel, R.J., Saldi, S.R.F., Dijk, L. van, Loveren, H. van, Cohen Tervaert, J.W., Klungel, O.H. Angiotensin-converting enzyme inhibitors or angiotensin II receptor blockers and the risk of developing rheumatoid arthritis in antihypertensive drug users. Pharmacoepidemiology and Drug Safety: 2012, 21(8), 835-843

72 Harrison DG, Guzik TJ, Lob HE, et al. Inflammation, immunity, and hypertension. Hypertension 2011; 57(2): 132-140.

73 Dessein PH, Norton GR. Should patients with RA be aggressively monitored for hypertension? Nat Clin Pract Rheumatol 2008; 4(1): 18-19.

\section{TABLES}

Table 1. Characteristics of study population at index date

\begin{tabular}{|c|c|c|c|}
\hline Characteristics & Cases, $n(\%)(n=211)$ & Controls, $n(\%)(n=667)$ & $p^{*}$ \\
\hline Age, years (mean $\pm S D$ ) & $69.6 \pm 11.2$ & $68.3 \pm 11.8$ & NS \\
\hline \multicolumn{4}{|l|}{ Gender } \\
\hline Male & $66(31.3)$ & $195(29.2)$ & NS \\
\hline Female & $145(68.7)$ & $472(70.8)$ & NS \\
\hline \multicolumn{4}{|c|}{ Duration registration at general practice, years ${ }^{\dagger}$} \\
\hline $1-5.99$ & $53(25.1)$ & $197(29.5)$ & NS \\
\hline $6-11.99$ & $93(44.1)$ & $286(42.9)$ & NS \\
\hline$\geq 12$ & $65(30.8)$ & $184(27.6)$ & NS \\
\hline \multicolumn{4}{|l|}{ Disease history before the index date $(\%)$} \\
\hline Hypertension & $134(63.5)$ & $421(63.1)$ & NS \\
\hline Diabetes & $31(14.7)$ & $125(18.7)$ & NS \\
\hline Cardiovascular disease & $95(45.0)$ & $219(32.8)$ & 0.001 \\
\hline Hyperlipidaemia & $58(27.5)$ & $165(24.7)$ & NS \\
\hline Hepatic disease & $6(2.8)$ & $14(2.1)$ & NS \\
\hline Renal disease & $4(1.9)$ & $8(1.2)$ & NS \\
\hline COPD & $31(14.7)$ & $27(4.1)$ & $<0.001$ \\
\hline Cancer & $9(4.3)$ & $33(5.0)$ & NS \\
\hline Inflammatory bowel syndrome & $2(0.3)$ & $2(1.0)$ & NS \\
\hline \multicolumn{4}{|l|}{ Drug use 6 months before the index date } \\
\hline Corticosteroids & $34(16.1)$ & $16(2.4)$ & $<0.001$ \\
\hline NSAIDs & $71(33.7)$ & $48(7.2)$ & $<0.001$ \\
\hline \multicolumn{4}{|l|}{ Antihypertensive drugs } \\
\hline Miscellaneous antihypertensive drugs & $0(0.0)$ & $8(1.2)$ & NS \\
\hline Thiazide diuretics & $95(45.0)$ & $277(41.5)$ & NS \\
\hline Beta blockers & $95(45.0)$ & $292(43.8)$ & NS \\
\hline Calcium channel blockers & $48(22.8)$ & 109 (16.3) & NS \\
\hline ACE inhibitors & $52(24.6)$ & $155(23.2)$ & NS \\
\hline ARBs & $32(15.2)$ & $76(11.4)$ & NS \\
\hline Aspirin & $28(13.3)$ & $87(13.0)$ & NS \\
\hline Antidiabetics & $23(10.9)$ & $85(12.7)$ & NS \\
\hline Lipid-lowering agents & $50(23.7)$ & $132(19.8)$ & NS \\
\hline HRT & $7(3.3)$ & $20(3.0)$ & NS \\
\hline Antibiotics & $40(19.0)$ & $83(12.4)$ & 0.02 \\
\hline Anti-psychotics & $1(0.5)$ & $6(0.9)$ & NS \\
\hline Antidepressants & $23(10.9)$ & $33(5.0)$ & 0.002 \\
\hline PPI & $47(22.3)$ & $52(7.8)$ & $<0.001$ \\
\hline
\end{tabular}

$\mathrm{NS}=$ not significant; $S D=$ standard deviation; $\mathrm{ACE}=$ angiotensin-converting enzyme; $\mathrm{ARBs}=$ angiotensin $I$ receptor blockers; $\mathrm{COPD}=$ chronic obstructive pulmonary disease; NSAIDs = nonsteroidal anti-inflammatory drugs; HRT = hormone replacement therapy; PPI = proton pump inhibitors.

*Chi-square test or Fisher exact test for comparison of proportions and Sudent's $t$-test for comparisons of means between cases and controls.

${ }^{\dagger}$ Duration of registration with a general practitioner was defined by the date of registry at a general practice or the first medical record of the patient.

Table 2. Association between use of angiotensin-converting enzyme inhibitors and angiotensin II receptor blockers and the risk of rheumatoid arthritis

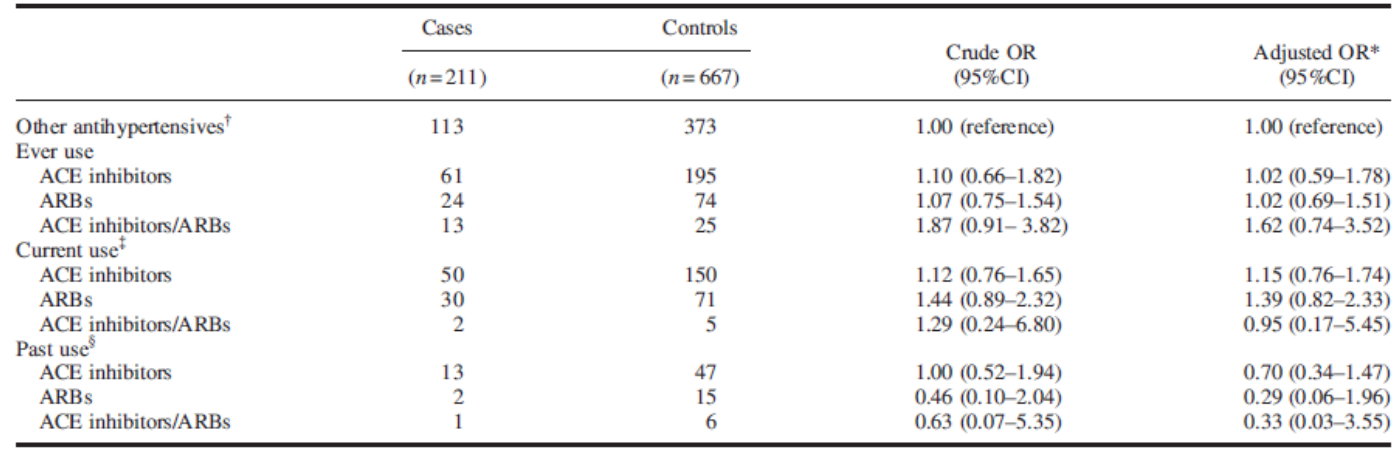

$\mathrm{ACE}=$ angiotensin-converting enzyme; $\mathrm{ARBs}=$ angiotensin $I I$ receptor blockers; $\mathrm{OR}=$ odds ratio; $\mathrm{CI}=$ confidence interval.

*Adjusted for age, gender, calendar year, history of cardiovascular diseases, and the use of NSAIDs, proton pump inhibitors, and calcium channel blockers. * Adjusted for age, gender, calendar year, history of cardiovascular diseases, and the use of NSAIDs, proton pump inhibitors, and calci

${ }^{\ddagger}$ Current users were patients who had received a prescription of ACE inhibitors and ARBs within 6 months prior to the index date.

${ }^{8}$ Past users were patients who received at least one prescription of ACE inhibitors and ARBs but discontinued treatment more than 6 months before the index date. 
Jong, H.J.I. de, Vandebriel, R.J., Saldi, S.R.F., Dijk, L. van, Loveren, H. van, Cohen Tervaert, J.W., Klungel, O.H. Angiotensin-converting enzyme inhibitors or angiotensin II receptor blockers and the risk of developing rheumatoid arthritis in antihypertensive drug users. Pharmacoepidemiology and Drug Safety: 2012, 21(8), 835-843

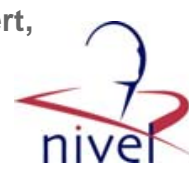

\begin{tabular}{|c|c|c|c|c|}
\hline & Cases & Controls & & \\
\hline & $(n=211)$ & $(n=667)$ & $(95 \% \mathrm{CI})$ & $(95 \% \mathrm{Cl})$ \\
\hline Other antihypertensives ${ }^{\dagger}$ & 113 & 373 & 1.00 (reference) & 1.00 (reference) \\
\hline \multicolumn{5}{|l|}{ Use of ACE inhibitors, days } \\
\hline $1-365$ & 19 & 61 & $1.04(0.59-1.81)$ & $0.90(0.50-1.62)$ \\
\hline $366-1095$ & 19 & 69 & $0.89(0.51-1.56)$ & $0.84(0.47-1.50)$ \\
\hline$>1095$ & 23 & 65 & $1.27(0.74-2.16)$ & $1.24(0.72-2.16)$ \\
\hline \multicolumn{5}{|l|}{ Use of ARBs, days } \\
\hline $1-365$ & 8 & 33 & $0.85(0.38-1.90)$ & $0.80(0.35-1.84)$ \\
\hline $366-1095$ & 10 & 29 & $1.12(0.53-2.36)$ & $0.93(0.42-2.05)$ \\
\hline$>1095$ & 6 & 12 & $1.82(0.66-5.06)$ & $1.64(0.57-4.69)$ \\
\hline \multicolumn{5}{|l|}{ Use of ACE inhibitors, DDD } \\
\hline$\leq 0.75$ & 17 & 64 & $0.90(0.50-1.62)$ & $0.83(0.44-1.58)$ \\
\hline $0.75-1.25$ & 27 & 70 & $1.34(0.82-2.21)$ & $1.28(0.75-2.21)$ \\
\hline$>1.25$ & 17 & 61 & $0.94(0.52-1.67)$ & $0.96(0.52-1.78)$ \\
\hline \multicolumn{5}{|l|}{ Use of ARBs, DDD } \\
\hline$\leq 1$ & 17 & 61 & $0.96(0.53-1.72)$ & $0.84(0.44-1.59)$ \\
\hline$>1$ & 7 & 13 & $1.71(0.66-4.43)$ & $2.03(0.72-5.76)$ \\
\hline
\end{tabular}

$\mathrm{ACE}=$ angiotensin-converting enzyme; $\mathrm{ARBs}=$ angiotensin $I I$ receptor blockers; $\mathrm{OR}=$ odds ratio; $\mathrm{CI}=$ confidence interval; $\mathrm{DDD}=$ defined daily dose.

*Adjusted for age, gender, calendar year, history of cardiovascular diseases, and the use of NSAIDs, proton pump inhibitors, and calcium channel blockers. ${ }^{\dagger}$ Other antihypertensives include calcium channel blockers, beta blockers, thiazide diuretics, and miscellaneous antihypertensive drugs.

\section{KEY POINTS}

- Use of ACE inhibitors or ARBs is not associated with incident RA.

- In contrast to the beneficial effects of ACE inhibitors and ARBs studied in patients with RA, we did not observe effects on the incidence of RA among patients initially free of RA.

- This study does not underline findings from individual case reports, suggesting that ACE inhibitors or ARBs may facilitate the development of autoantibodies and/or autoimmune disease.

- Based on our findings, both ACE inhibitors and ARBs are considered to be safe for patients with a risk of developing RA. 